\title{
Using Purchasing Power Parity to Assess Construction Productivity
}

Rick Best, (Bond University, Australia)

\begin{abstract}
For many reasons comparing construction productivity between countries is a difficult task. One key problem is that of converting construction costs to a common currency. This problem can be overcome relatively simply by using a basket of construction materials and labour, termed a BLOC (Basket of Locally Obtained Commodities), as a unit of construction cost. Average BLOC costs in each location are calculated from data obtained from a number of sources (quantity surveyors, estimators). Typical building costs obtained from published construction cost data are expressed in BLOC equivalents. Lower BLOC equivalents represent higher productivity as other inputs (largely materials) are constant. The method provides a relatively simple and direct method for comparing productivity between different locations.
\end{abstract}

Keywords: International construction, Industry comparisons, Purchasing power parity, Construction productivity

\section{Introduction}

Assessing the relative productivity of the construction industries of different countries is a difficult task (OECD/Eurostat, 2001; Loosemore and McGeorge, 2002; Bernstein, 2003), however, the importance of the construction sector in most national economies means that various stakeholders, and governments in particular, are interested in such comparisons. In Australia in 2007-08 all construction accounted for just over $16 \%$ of GDP and $57 \%$ of gross capital formation (Table 1: ABS, 2008).

\begin{tabular}{|c|c|c|}
\hline $\begin{array}{c}\text { GDP } \\
\text { (AUD } \times \mathbf{1 0}^{\mathbf{6})}\end{array}$ & $\begin{array}{c}\text { All construction as } \% \text { of } \\
\text { GDP }\end{array}$ & $\begin{array}{c}\text { Construction as } \% \text { of gross } \\
\text { capital formation }\end{array}$ \\
\hline $\mathbf{2 0 0 7 - 0 8}$ prices & $16.2 \%$ & $57 \%$ \\
\hline $1,132,172$ & & $57 \%$ \\
\hline
\end{tabular}

Table 1 GDP, contribution of construction to GDP and gross capital formation in Australia for 2007-8 (Source: ABS, 2008)

Given the amount that construction contributes to GDP, even modest improvements in efficiency can translate into significant increases in growth, and growth is a common measure of the health of modern economies. Comparative studies have been attempted since at least the late 1940s (Anglo-American Council on Productivity, 1950) and many different methodologies have been used, with varying degrees of success and notable inconsistency in the results obtained. The difficulty is always in devising readily applicable and reliable metrics to allow measurements and subsequent comparisons to be made. In construction the difficulties of formulating the required measuring tools are increased for a variety of reasons including the heterogeneous nature of construction output (UN, 1992; Vermande and van Mulligen, 1999), which makes measuring and comparing output problematic, and the highly subjective nature of quality in construction (Flanagan et al. 1986; Rittenau, 2002), relating as it does not only to workmanship, finish and incidence of defects, but also to quality of design (primarily in terms of functionality and aesthetics). Highly specialised metrics are required if useful comparisons are to be made possible. 
At a macroeconomic level total industry output may be aggregated but there is only one available unit of measure and that is money; it is impossible to aggregate output in any other way when the built facilities that comprise that output are of myriad types and sizes, each with its own set of unique characteristics relating to function, site, materials, climate, quality and so on.

Even at a micro level, when comparing onsite tasks such as the placement of ready-mixed concrete or the application of plaster or render, there are differences between projects. Factors such as climate affect building operations: concrete placement, for example, is a different task in an Australian summer to that in a Canadian winter. Similarly requirements and regulations pertaining to the safety of workers on building sites vary from place to place: the use of bamboo scaffolding, commonplace in Hong Kong, would be impossible in New York or London.

The purpose here is to describe a method for measuring relative productivity that may eliminate some of the problems associated with assessing construction productivity.

\section{Measuring Construction Productivity}

Productivity measurement can be approached in many ways, from broad macroeconomic measures (e.g. Croce et al., 1999) to onsite measurements of specific construction activities (e.g. Oglesby et al., 1989). The simple definition of productivity, output over input, is not particularly useful in the construction context. There are many reasons why making such a calculation is difficult and they include:

- the products of the construction industry are rarely exactly the same (OECD/Eurostat, 2001:24)

- inputs need to be expressed in a common unit, usually money, but factors such as management, organisation and ingenuity (English and Marchione, 1983:58) are difficult to express in dollars.

- completed buildings (output) tend to be neither produced nor sold by a single contractor (OECD/Eurostat, 2001:10).

Since 1980 a number of partial productivity studies have been reported in which the authors have used macroeconomic data, gathered by national statistics offices or international groups such as the OECD. Such studies have been criticised for a variety of reasons including:

- failure to provide data on quality (Kaglioglou et al., 2001:86; Goodrum et al., 2002:416)

- too simple to be an adequate measure of overall productivity in an economic sector as large and complex as construction (Bernstein, 2003:47)

- cost effective but with suspect reliability and comparability of data (Xiao et al., 2000)

- too lacking in detail to be of use below the whole-of-industry level (Proverbs and Faniran, 2001:385)

- an unsatisfactory measure of efficiency of utilisation of resources (Chau and Walker, 1988:209) 
- failure to reflect differences in capital intensity in measures such as output per hour worked or per person employed (de Valence, 2001:695)

Edkins and Winch (1999:19) suggest that they are a "crude" measure, particularly of output, and voice a number of concerns including the use of methodology that can be criticised as invalid as they use data from disparate sources. More recently BWA (2006:75) suggest that all methods for "international construction cost efficiency comparisons" that use macroeconomic statistics are invalid or at least unreliable.

\section{A Purchasing Power Approach}

The great majority of international industry comparisons require that costs expressed in various national currencies be brought to a common base, typically US dollars (USD). It is generally acknowledged that money market or "nominal" exchange rates do not provide a reliable method for doing this (e.g. Vermande and van Mulligen, 1999; Goodchild and Griffiths, 2004; Blake et al., 2004). It has been suggested that purchasing power parity (PPP) provides a more robust basis for such currency conversions (Walsh and Sawhney, 2002; Langston and Best, 2005; Best and Langston, 2006) and that industry specific PPPs are required if reliable comparisons are to be made (Schreyer and Koechlin, 2002; Stapel, 2004).

The idea of purchasing power parity (PPP) can be traced as far back as the 16th century (Dornbusch, 1987). It is based on what Rogoff (1996:647) describes as "the disarmingly simple empirical proposition" that the cost of a good or service (or a basket of goods and services), once prices are converted to a common currency, should cost the same in different countries This is the so-called Law of One Price (Pakko and Pollard, 1996; Lafrance and Schembri, 2002; UBS, 2003). The theory is that if an item can be bought more cheaply in country $A$ than in country $B$ then traders can profit by buying in country $A$ and selling in country $B$. This is known as arbitrage. The theory suggests that over time international trade will see the price of the item in both countries level out.

Dubner and McKenzie (2002) examined a number of options for producing constructionspecific PPPs (CPPPs) including the standard projects approach currently used by Eurostat to gather construction sector data for its GDP level PPP program and the basket of goods approach (similar to a typical Consumer Price Index method) tested by Stapel (2002) and Meikle (2003). Walsh and Sawhney $(2002,2004,2005)$ developed a basket of construction components for the World Bank.

Best (2008) developed and tested a fixed weight basket of construction materials and labour for use in comparing the construction costs of hotel buildings. It was similar in some respects to Meikle's but with some significant differences. The most significant difference was in the selection and weighting of the items in the basket; where Meikle selected the items in his basket on an ad hoc basis and used input-output tables to establish weights, Best populated his basket by identifying the most cost significant items in the contractor's priced bill of quantities for a completed hotel project and established weights based on the relative quantities of various components in the same project. The basket is referred to as a BLOC, derived from Basket of Locally $\underline{\text { Obtained }}$ Commodities.

The reference project was a single building type of a defined standard (3-4 star hotel) constructed in 2003, located just outside Sydney's CBD. Hotels of medium to high standard are generally similar in terms of size, layout and finish regardless of location, with hotels that belong to international chains such as Marriott, Hilton and Sofitel displaying very similar characteristics wherever they are located. This is particularly true if the properties are located in major cities in developed countries. Medium standard hotels were selected for this study as a building type that could be easily identified and described, and that respondents in the various locations could easily recognise based on their own experience even though

Best, R (2010) 'Using purchasing power parity to access construction productivity', Australasian Journal of Construction Economics and Building, 10 (4) 1 - 10 
there is no internationally agreed rating system for hotels. Pricing rounds were conducted only in major cities in developed countries, where such buildings are common.

In each major trade section one item was selected and assumed to represent all similar items in the $B Q$, e.g. in the masonry trade concrete blocks were identified as the most cost significant item. From the $B Q$ analysis it was determined that AUD $\$ 117,638$ (out of a trade total of $\$ 229,759$ ) was in "hollow block" items. Published data (Cordell, 2007) suggests a labour/materials ratio of $64: 36$ for hollow blockwork so block supply cost was calculated as $0.36 \times \$ 117,638=\$ 42,350$. From the $B Q 140$ hollow blocks were determined as the most commonly occurring type of block and these were then assumed to represent blocks of all types, i.e. 140 blocks then became the material item representing the masonry trade, and thus the masonry item included in the basket.

To derive quantities for each material item in the basket the total cost (supply only) for each item was divided by the unit supply cost for each item (Cordell, 2003). These quantities set the scale of the quantities for the materials in the basket, based on the size of the reference project. It is suggested that the derived quantities indicate only the scale of the quantities of the particular type of material in the sample project, e.g. 140 hollow blocks as the material representing all blocks in the project.

Labour required for installation of the material items in the basket was identified (e.g. block laying as $80 \%$ tradesman and $20 \%$ semi-skilled labourer) and weights calculated based on the relative weights of labour and materials for each item. For example, as noted above, for hollow blocks the labour/materials split is $64: 36$ and the derived supply cost $\$ 42,350$. The labour cost associated with that quantity of blocks is then:

$$
\frac{\$ 42,350 \times 0.64}{1-0.64}=\$ 75,289
$$

and of that amount $80 \%(\$ 60,231)$ is for tradesmen and $20 \%(\$ 15,058)$ is semi-skilled labour.

A similar method was used for each item in the basket and a total labour cost as well as a separate figure for each relevant class of labour was calculated. Using published hourly labour rates for Sydney for 2003 (Cordell, 2003) the total number of hours of each class of labour required for the installation of given quantities of the various materials in the basket was then determined.

The BLOC was priced by varying numbers of quantity surveyors and construction estimators in six cities: three in Australia (Sydney, Melbourne, Brisbane) plus Auckland, Singapore and Phoenix. Percentage allowances for preliminaries and contractors' mark-ups were added based on data gathered as part of the pricing survey. Costs excluded value added tax in order to align BLOC costs with the superficial project costs used in the productivity comparison. BLOC costs were also adjusted to reflect prevailing market conditions in each city as input costs, particularly for labour, and profit margins can be expected to vary in response to the amount work available in the market at any given time. It is a feature of the BLOC method that basic input costs can be used as a basis for comparisons but equally these base costs can be adjusted to account for overheads, profit, taxation and market conditions depending on the specific comparison that is being undertaken.

The cost data obtained contained some apparent anomalies, particularly in the costs given for materials. Respondents were asked for "supply only" rates for materials but many were noted as "supply and fix" while others appeared to be too high to be supply only rates but were not qualified by any comment from the respondents. Supply and fix rates were 
discarded as labour and materials were specifically separated in the BLOC. Rates which simply appeared to be incorrect presented a much more difficult problem as it was deemed inappropriate to discard data simply because it looked or felt wrong. Where possible respondents were asked for clarification; where this was not possible or queries went unanswered published cost information was used (e.g. RSMeans, 2008) for comparison.

Potential anomalies were identified by looking at the spread of material cost data for each BLOC item. The coefficient of variation (CoV) for dataset was calculated and items with a CoV exceeding $40 \%$ were revisited with suspect rates being investigated in more detail, often by contacting suppliers directly or asking personal contacts in the various cities to seek more detailed data.

The average cost of the BLOC in each city was the used to produce CPPPs that could be used to convert construction costs in different currencies to a common base with price differences removed, thus producing "real" rather than "nominal" exchange rates.

Apart from its use for the compilation of CPPPs the results allowed simple and direct comparisons of construction productivity between cities.

\section{Using the Basket to Assess Productivity}

In this section two comparisons are used to illustrate how the method may be used. In each case the results from two cities are used; in the first example productivity is compared between two Australian cities, Sydney and Brisbane, with raw cost data all in AUD. In the second Sydney and Phoenix are the subjects and raw costs are in AUD and USD respectively. Cost data for the BLOC were obtained from 19 respondents in Sydney and seven in both Brisbane and Phoenix. Following the validation exercise outlined above average rates for each BLOC item in each location were calculated. Total BLOC costs were then derived for the various locations. Based on the notion of PPP the costs of the BLOC in Australian dollars (AUD) in Sydney and Brisbane represents the same value as the cost of the BLOC in USD in Phoenix, thus the ratio of the BLOC cost in one location to that in another location produces a simple CPPP. In each case BLOC costs are expressed in national currencies and these do not need to be converted to a common currency as, in effect, a new "currency" has been created, that of BLOC equivalents. This idea of BLOC equivalents is discussed further below.

\section{The Sydney-Brisbane Comparison}

The average cost of the basic BLOC (excluding tax) in Sydney was AUD 11,592,455 (January 2008 prices) and in Brisbane AUD 11,621,932. The ratio of the cost of the BLOC in the two cities is close to unity. This is not surprising given that the cities are reasonably similar in most ways and many of the same construction companies operate in both cities. Labour is mobile and relocation between the two cities is common so labour rates do not vary significantly and materials supply is similar.

The average BLOC costs were used to assess relative construction productivity between the two cities by using the BLOC as a unit of construction costs. This method parallels the method employed by Langston and de Valence (1999) who used the Big Mac Index (BMI) to express building costs in various national currencies in hamburgers $/ \mathrm{m}^{2}$ by dividing project costs in each local currency by the local cost of a Big Mac. The same can be done by using construction costs at the project level expressed as the number of BLOCs that equal the cost of a project, calculated by dividing the cost for a project by the cost of the BLOC with both costs expressed in the same local currency.

Using published cost $/ \mathrm{m}^{2}$ rates (RLB, 2008a) the cost of a hypothetical hotel building was calculated in terms of the equivalent number of BLOCs in the two cities. Table 2 shows the

Best, R (2010) 'Using purchasing power parity to access construction productivity', Australasian Journal of Construction Economics and Building, 10 (4) 1 - 10 
outcomes and indicates the relative cost in BLOC equivalents of a $10,000 \mathrm{~m}^{2}$ hotel in the two locations, with Sydney as the base $(\mathrm{BI}=100)$. Project costs are based on median rates for three star hotels from RLB (Rider Levett Bucknall).

\begin{tabular}{|c|c|c|c|}
\hline CITY & $\begin{array}{c}\text { Project cost } \\
\text { (Local currencies } \\
\text { millions) }\end{array}$ & $\begin{array}{c}\text { BLOC } \\
\text { equivalent }\end{array}$ & $\begin{array}{c}\text { BLOC } \\
\text { Index }\end{array}$ \\
\hline Sydney & 23.85 & 2.057 & 100.00 \\
\hline Brisbane & 32.25 & 2.775 & 134.90 \\
\hline
\end{tabular}

Table 2 Project costs for Sydney and Brisbane expressed in local currencies and BLOC equivalents, and BLOC Index values derived from those BLOC equivalents

The comparison between Sydney and Brisbane summarised in Table 2 shows that a typical $10,000 \mathrm{~m}^{2}$ hotel building in Sydney would cost AUD23.85m and the same type and size hotel building in Brisbane would cost AUD32.25m. Even allowing for variations in cost $/ \mathrm{m} 2$ rates and variations in BLOC pricing Sydney is shown to be a more productive location in terms of the ratio of labour input to construction output. As the quantity of materials in the BLOC is constant differing BLOC equivalents (i.e. construction cost divided by BLOC cost) can only mean that different amounts of labour were required in order to install the materials in the BLOC. As the cost of the hypothetical hotel expressed as the number of BLOC equivalents is considerably lower in Sydney it follows that that the industry in Sydney is more productive than in Brisbane.

\section{The Sydney-Phoenix Comparison}

The average cost of the BLOC in Phoenix was USD 7,729,634; in Sydney it was AUD $11,592,455$. At the time of the study (early 2008) the CPPP for comparing construction costs between the two cities was therefore:

$$
\frac{11,592,455}{7,729,634}=1.500
$$

i.e. one USD would buy the same amount of construction in Phoenix as AUD1.500 would in Sydney. At the same time the nominal exchange rate was $1 \mathrm{USD}=1.104 \mathrm{AUD}$; this highlights the disparity between nominal exchange rates and PPPs.

As in the previous comparison the $t$ average BLOC costs were used to assess relative construction productivity between the two cities by using the BLOC as a unit of construction costs. Using published cost/m2 rates (RLB, 2008a; 2008b) the cost of a similar hypothetical hotel building was calculated in terms of the equivalent number of BLOCs in the two cities. Table 3 shows the outcomes. Note that nominal exchange rates play no part in this comparison as BLOC costs for both locations were compiled in local currencies and building costs are similarly expressed in local currencies.

\begin{tabular}{|c|c|c|c|}
\hline CITY & $\begin{array}{c}\text { Project cost } \\
\text { (Local currencies } \\
\text { millions) }\end{array}$ & $\begin{array}{c}\text { BLOC } \\
\text { equivalent }\end{array}$ & $\begin{array}{c}\text { BLOC } \\
\text { Index }\end{array}$ \\
\hline Sydney & 23.85 & 2.057 & 100.00 \\
\hline Phoenix & 18.29 & 2.366 & 115.02 \\
\hline
\end{tabular}

Table 3 Project costs for Sydney and Phoenix expressed in local currencies and BLOC equivalents, and BLOC Index values derived from those BLOC equivalents. 
The comparison between Sydney and Phoenix in Table 3 shows that a typical $10,000 \mathrm{~m} 2$ hotel building in Sydney would cost AUD23.85m and the same type and size hotel building in Phoenix would cost USD18.29m (based on cost/m2 rates from RLB, 2008a and 2008b). As in the previous example Sydney is shown to be a more productive location in terms of the ratio of labour input to construction output.

\section{Discussion}

It should be noted that to produce valid purchasing power parities the items in the BLOC must have the same fixed weights for all locations. Pakko and Pollard (1996:5) say that the Law of One Price only leads to purchasing power parity under certain conditions. They suggest that as a PPP index is built up from a number of weighted average prices for various items then the Law of One Price will only produce PPPs if the same items and their respective weights are the same for all locations. This means that the same single standard basket of items is used to gather prices in all locations. This is an essential element of the PPP approach and it assumes that productivity is the same in each location. Differences in BLOC equivalents between locations, however, indicate that productivity varies as if we are comparing identical buildings then the quantities of materials must be identical - hence differences in BLOC equivalent cost must indicate differing productivity. As in any modelling exercise certain assumptions are made that are unlikely to hold perfectly in practice; in this case the assumption of equal productivity between locations is a key assumption but differing BLOC equivalent project costs indicate that it cannot be correct. It is clear that while it is not possible to construct identical projects with different quantities of materials it is possible to do so with different quantities of labour. Thus, if BLOC equivalents for identical projects differ it can only be due to differences in the quantity of labour required to install a fixed quantity of materials, and more labour for the same result must imply lower productivity.

The assumption behind the use of fixed quantities of all inputs is that the buildings and the technology of construction are identical. The assumption of identical technologies is common in economic theory, e.g. implicitly in perfect competition in micro-economic theory and explicitly in comparative advantage in international trade theory (see for instance Grubel, 1977).

If this assumption is satisfied, it means that the PPP reflects differences in the costs of inputs only. Therefore, the BLOC will also function as a measure of relative productivity between various locations.

Assume two locations, A and B, in the same country. They share the same currency and tax regime but construction costs may vary between the two locations. If a standard basket of construction goods (the BLOC) is priced in each location, and overall input costs (labour and/or materials) are cheaper in A than in B then naturally the cost of the BLOC will be less in $\mathrm{A}$.

Assume two identical buildings are built in the two locations and the construction costs in both cases are the same. The cost of the building can be expressed in BLOCs by dividing the cost of the building by the cost of the BLOC in each location. As the cost of the BLOC in $A$ is lower than the cost of the BLOC in B, the building cost in A, expressed in BLOCs, will be higher than in $B$ although the dollar cost is the same. Alternatively it can be said that construction price levels in $B$ are higher than in $A$.

If the buildings are identical the quantities of materials used must be identical. The variable factor is labour. If the building cost in $A$ is represented by a greater number of BLOCs the amount of labour required in A to install the materials in the BLOC (measured in hours, not dollars) must be greater. Differences in costs expressed in the number of BLOCs required do not originate in materials that are the same in both buildings - they must be the result of

Best, R (2010) 'Using purchasing power parity to access construction productivity', Australasian Journal of Construction Economics and Building, 10 (4) 1 - 10 
more or less labour being required. In the example, given that more labour is required to install the fixed quantities of materials in the BLOC, the labour in A must be less productive.

The same logic applies even if the building cost varies between $A$ and $B$, as the building cost is being measured using the BLOC as a common unit of construction cost or resources required. It applies equally where the two locations do not share the same currency as in any given location both building cost and BLOC cost are initially measured in the same local currency. Building costs per $\mathrm{m}^{2}$ expressed in BLOC equivalents are directly comparable as they are expressed in the same units. As materials quantities in the BLOC are constant, fewer BLOC equivalents indicate higher labour productivity.

\section{Conclusions}

This study shows describes a relatively straightforward method for assessing relative construction productivity between locations, even where construction output, measured in money, is expressed in different currencies. If robust sets of basket (input) costs are collected from each location then many of the problems associated with other productivity comparison are avoided. These include the problems associated with macroeconomic data that is often not collected in the same way in different countries and are therefore not necessarily comparable, and the problems associated with the use of money market exchange rates to bring costs to a common currency base.

The method described does not provide absolute productivity comparisons; it is based on a model that is a simplification of the real world situation and as such can only provide indicative outcomes, not perfect relativities.

\section{References}

ABS (2008) Australian System of National Accounts, 2007-08. Australian Bureau of Statistics http://www.abs.gov.au/AUSSTATS/abs@.nsf/DetailsPage/5204.02007-08?OpenDocument

Anglo-American Council on Productivity (1950) Productivity Team Report on Building, Report of a visit to the USA in 1949 of a productivity team representing the building industry

Bernstein, H. (2003) Measuring productivity: An Industry Challenge. Civil Engineering, December, 46-53

Best, R. (2008) The development and testing of a purchasing power parity method for comparing construction costs internationally. Unpublished PhD thesis, University of Technology, Sydney

Best, R. and Langston, C. (2006) Converting construction costs to a common currency base: an unresolved problem. In: Proceedings of Construction in the XXIst Century: Local and Global Challenges. Rome, October 18-20

Blake, N., Croot, J. and Hastings, J. (2004) Measuring the Competitiveness of the UK Construction Industry: Volume 2. Experian Business Strategies, Department of Trade and Industry, London

BWA (2006) Benchmarking of use of Construction (Costs) Resources in the Member States (Pilot Study), Bernard Williams Associates, London

Chau, K. and Walker, A. (1988) The measurement of total factor productivity of the Hong Kong construction industry, Construction Management and Economics, 6, 209-224

Cordell (2003) Commercial and Industrial Building Cost Guide, New South Wales, Reed Construction Data

Cordell (2007) Commercial and Industrial Building Cost Guide, New South Wales, Reed Construction Data 
Croce, N., Green, R., Mills, B. and Toner, P. (1999) Constructing the Future: A Study of Major Building Construction in Australia, Employment Studies Centre, University of Newcastle

de Valence, G. (2001) Construction deflators and measurement of output. In: Akintoye, A (ed.), 17th Annual ARCOM Conference, 5-7 September 2001, University of Salford. Association of Researchers in Construction Management, Vol. 1, 693-701

Dornbusch, R. (1987) Purchasing power parity. In: Eatwell. J., Milgate. M. and Newman. P. (eds), The New Palgrave: a dictionary of economics. Macmillan, 1075-1085

Dubner, M. and McKenzie, R. (2002) Construction Industry Purchasing Power Parities Obtaining Comparable Prices, Conference on the International Comparison Program, Washington, D.C., March 11-14, www.worldbank.org/data/icp/documents/dms.doc

Edkins, A. and Winch, G. (1999) The Performance of the UK Construction Industry: An International Perspective. Bartlett Research Papers

www.bartlett.ucl.ac.uk/cem/AreaFrame/Research/download/bartresearch/\#top

English, J. and Marchione, A. (1983) Productivity: A New Perspective. California Management Review, 25 (2), January, 57-66

Flanagan, R., Norman, G., Ireland, V. and Ormerod, R. (1986) A Fresh Look at the UK \& US Building Industries, Building Employers Confederation, London

Goodchild, G. and Griffiths, D. (2004) New Zealand's involvement in the joint OECDEurostat Purchasing Power Parities Programme, Statistics New Zealand Information Paper 2004

Goodrum, P., Haas, C. and Glover, R. (2002) The divergence in aggregate and activity estimates of US construction productivity, Construction Management and Economics, 20, 415-423

Grubel, H. (1977) International Economics, R. D. Irwin, Homewood. Illinois

Kagioglou, M., Cooper, R. and Aouad, G. (2001) Performance management in construction: a conceptual framework, Construction Management and Economics, 19, 85-95

Lafrance, R. and Schembri, L. (2002) Purchasing-Power Parity: Definition, Measurement and Interpretation. Bank of Canada Review, Autumn, 27-33

Langston, C. and de Valence, G. (1999) International Cost of Construction Study - Stage 2: Evaluation and Analysis, Department of Industry Science and Resources, Canberra. www.isr.gov.au/library/content_library/BC-CoCStage2.pdf

Langston, C. and Best, R. (2005) Using the Big Mac Index for comparing construction costs internationally. In: Sidwell, A. (ed) Proceedings of QUT Research Week 2005, Queensland University of Technology, July

Loosemore, M. and McGeorge, D. (2002) Workplace Regulation, Reform and Productivity in the International Building and Construction Industry, Discussion Paper 15, Royal Commission into the Building and Construction Industry. www.royalcombci.gov.au/docs/Complete\%20Discussion\%20Papper\%2015.pdf

Meikle, J. (2003) Eurostat capital goods price comparison study, Davis Langdon Consultancy

OECD/Eurostat (2001) Sources and Methods - Construction Price Indices, Statistics Directorate, OECD (Paris) and Statistical Office of the European Community, Luxembourg

Oglesby, C., Parker, H. and Howell, G. (1989) Productivity Improvement in Construction, McGraw-Hill

Pakko, M. and Pollard, P. (1996) For Here or To Go? Purchasing Power Parity and the Big Mac, Federal Reserve Bank of St. Louis Review, 78 (1), 3-21 
Proverbs, D. and Faniran, O. (2001) International construction performance comparisons: a study of 'European' and Australian contractors, Engineering, Construction and Architectural Management, 8 (4) 284-291

Rittenau, R. (2002)The Great Estimate, Conference on the International Comparison Program, Washington, D.C., March 11-14

RLB (2008a) Riders Digest - Sydney 2008. Rider Levett Bucknall, www.oceania.rlb.com/documents/cost-research/cost-research_riders-digest/scn/2008.pdf

RLB (2008b) Riders Digest - USA 2008. Rider Levett Bucknall, www.americas.rlb.com/documents/cost/digest/2008_1.pdf

Rogoff, K. (1996) The Purchasing Power Parity Puzzle, Journal of Economic Literature, XXXIV, 647-668

RSMeans (2008) Building Construction Cost Data, $66^{\text {th }}$ edition, Reed Cost Data

Schreyer, P. and Koechlin, F. (2002) Purchasing power parities - measurement and uses, OECD Statistics Brief, March, No. 3

Stapel, S. (2002) The Eurostat Construction Price Surveys: History, Current Methodology and New Ways for the Future, Conference on the International Comparison Program, World Bank, Washington, 11-13 March

Stapel, S. (2004) Challenging the 'snapshot theory' of Purchasing Power Parities: Eurostat's revision of the PPP 1995 to 2000 ,

www.ipeer.ca/papers/Stapel,June6,2004,_final_04_6_04.pdf.

UBS (2003) Prices and Earnings: A Comparison of Purchasing Power Parity around the Globe (2003 Edition), Union Bank of Switzerland

UN (1992) Handbook of the International Comparison Programme, United Nations

Vermande, $\mathrm{H}$. and van Mulligen, P-H. (1999) Construction costs in The Netherlands in an international context, Construction Management and Economics, 17, 269-283

Walsh, K. and Sawhney, A. (2002) International Comparison of Cost for the Construction Sector: Towards a Conceptual Model for Purchasing Power Parity. Report submitted to the World Bank Group, June 2002

Walsh, K. and Sawhney, A. (2004) International Comparison of Cost for the Construction Sector: An Implementation Framework for the Basket of Construction Components Approach, Report submitted to the African Development Bank and the World Bank Group, June 2004

Walsh, K. and Sawhney, A. (2005) International Comparison of Cost for the Construction Sector: Identification of Construction systems and components for the BOCC approach, Report submitted to the World Bank Group, November 2005

Xiao, H, Proverbs, D, Shaw, T. and Holt, G. (2000) A new approach to comparing the performance of contractors internationally. Proceedings of 16th ARCOM Conference, Glasgow Caledonian University 